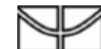 \\ e-Boletim de Física \\ International Centre for Condensed Matter Physics \\ Instituto de Física, Universidade de Brasília \\ Ano II, junho de 2013 www. boletimdafisica.com eBFIS 2, 007 (2013)
}

\section{Energia escura: o estado da arte}

\author{
Sérgio C. Ulhoa \\ Faculdade Gama, Universidade de Brasília, 72444-240, Brasília-DF, Brasil \\ Centro Internacional de Física da Matéria Condensada, Instituto de Física, \\ Universidade de Brasília, 70910-900, Brasília, DF, Brasil
}

\begin{abstract}
Nesse trabalho tratamos de modo breve das principais abordagens para explicar a chamada energia escura. Fundamentamos a apresentação no desenvolvimento histórico do tema. Discutimos a importância da constante cosmológica no processo de expansão acelerada do Universo e consideramos alternativas para explicar tal fato: convencionais, como o campo escalar, e não-convencionais, como a idéia de que isso possa ser devido a um efeito de referencial acelerado.
\end{abstract}

Desde os primórdios dos tempos a humanidade tem observado os movimentos cósmicos e interpretado suas conseqüências. Inicialmente tais observações foram fundamentais no planejamento de colheitas e previsão das estações do ano o que permitiu grandes assentamentos humanos e consequente desenvolvimento de civilizações. Esse processo se deu de tal modo que um profundo significado religioso foi associado ao céu noturno. Assim o conhecimento da humanidade foi por longos séculos fenomenológico, no sentido de que era essencialmente ligado à observação (e não necessariamente à experimentação científica), não existindo uma modelo teórico, que fosse de fato matemático, capaz de formalizar tais observações. Claro que existiam explicações filosóficas como o modelo de Aristóteles com as esferas celestes concêntricas preenchidas por éter [1].

Com o advento da lei da gravitação universal foi possível, pela primeira vez na história da humanidade, o entendimento da força que governa os fenômenos cósmicos: a gravidade. Assim a humanidade foi capaz de prever o movimento dos corpos celestes da mesma forma que podia prever a trajetória de sistemas na Terra do ponto de vista da cinemática e dinâmica. Nesse sentido se diz que Newton unificou o céu e a terra [2]. Dessa forma a astronomia ganhava o formalismo matemático imprescindível ao seu desenvolvimento como ciência permitindo que objeto como os cometas, antes vistos como sinais da fúria dos deuses ou como gatilho do apocalispse, ganhassem uma conotação prática.

Apesar do grande sucesso da teoria newtoniana, ainda faltava uma teoria que determinasse a evolução do Universo como um todo e não somente alguns objetos específicos, ou seja, a pergunta crucial de como as galáxias se movimentam no infinito não estava re- spondida, nem sequer bem compreendida. Em 1915 Albert Einstein deu um passo fundamental para esse entendimento ao apresentar a teoria da relatividade geral, que era uma generalização dos seus trabalhos de 1905 [3]. As equações de Einstein relacionavam uma nova geometria, a Riemanniana, com a quantidade de matéria e energia presente no espaço. Assim a matéria definia a geometria do chamado espaço-tempo, que seria uma construção abstrata definida pela união das coordenadas espaciais e temporal, e essa geometria determinava o movimento da matéria. Nesse ponto o Universo poderia ser modelado a partir de um único conjunto de equações, pois não só tinha-se o entendimento da força gravitacional como agente ativo no movimento dos corpos celestes, como também uma maneira de determinar a forma e evolução do espaçotempo que nesse caso era o próprio Universo.

Logo após Einstein ter escrito suas equações, Friedmann, partindo do pressuposto que o Universo é isotrópico e homogêneo, escreveu um conjunto de equações que determinava a evolução do Universo [4]. Os únicos parâmetros livres em tais equações eram ligados à observação, ou seja, a própria curvatura do Cosmos. Esse conjunto de equações demonstravam um Universo dinâmico e dependente da quantidade de matéria e energia existentes. Entretanto, utilizando apenas as equações de Friedmann não era possível explicar certos dados experimentais o que levou ao desenvolvimento de um complemento teórico, conhecido como inflação cuja ação teria se dado nos primórdios dos tempos. Assim a visão do Universo que se tinha em larga escala era a de um gás disperso, sendo as "partículas" do gás as próprias galáxias. É interessante notar que a cosmologia no início do século vinte era essencialmente experimental e é nesse con- 
texto que se encaixam as experiências de Hubble. Ele descobriu que as galáxias não estavam fixas no céu como se acreditou durante muitos séculos. Sua principal hipótese era de que a velocidade de afastamento das galáxias era proporcional à distância em relação à Terra (lembrando que em um Universo homogêneo e isotrópico é possível tomar o nosso planeta como origem do sistema de coordenadas). Hubble descobriu um valor muito maior para essa constante (que foi nomeada em homenagem a ele) do que o valor que hoje entendemos como mais acurado [5]. O problema é que a hipótese de Hubble só tem validade para galáxias relativamente próximas, cerca de um megaparsec. Hoje em dia o valor aceito para a constante de Hubble é $\mathrm{H}=72 \mathrm{Km} /$ (s. Mpc).

Na década de noventa do século passado um conjunto de pesquisadores descobriu algo surpreendente: o Universo está em expansão acelerada [6]. Esse fato passou a ser explicado pela introdução de uma energia exótica, chamada de energia escura. O desafio atual consiste em determinar a natureza da energia escura. Antes dessa descoberta, os pesquisadores acreditavam que a gravitação iria dominar a expansão do universo, o que iria desacelerá-lo, causando o fenômeno do "big crunch". Hoje a idéia é justamente o crontrário, ou seja, a energia escura se tornará cada vez mais dominante acelerando o Universo até que todas as estruturas de matéria sejam rompidas, inclusive o "tecido" do espaço-tempo. Isso é conhecido como o "big rip".

O próprio Einstein acreditava que o Universo era estático. Tal princípio conjugado com as equações de movimento da relatividade geral forçavam a introdução de um campo (de maneira inteiramente "ad hoc" que equilibrasse a atração gravitacional. Esse foi exatamento o procedimento adotado por Einstein que chamou esse campo de "constante cosmológica". A hipótese do Universo estático nunca foi confirmado pelo experimento, aliás Hubble demostrou justamente o contrário. Mais tarde Einstein viria a dizer que a introdução da constante cosmológica foi o seu maior erro. Atualmente a hipótese mais bem aceita para explicar a energia escura é justamente a constante cosmológica, que tem um comportamento incrivelmente parecido com o que observamos para a energia escura
[7]. Muitos acreditam que isso não pode ser mera coincidência. Nesse sentido parece que mesmo quando Einstein erra, ele acerta!

Uma outra hipótese bastante popular na comunidade científica é aquela relativa à introdução de um campo escalar. Consideramos que as equações de Einstein tem como princípio a relação entre a curvatura do espaço-tempo e a quantidade de matéria-energia presente nele. Pois bem, se a gravitação estiver acoplada a um campo escalar então é possível ajustar esse campo para reproduzir aquilo que é observado [8]. Assim é possível estabelecer todas as características que definem o campo escalar e sua atuação no espaço-tempo como por exemplo a sua pressão.

Outra hipótese surgida nos últimos anos afirma que a energia escura não tem existência real, mas seria conseqüência de alguma característica do sistema. A proposta se baseia na ideia de que a energia escura seria um efeito de referencial, devido ao fato de que a Terra (normalmente usada como referência para a observação) estar em movimento acelerado [9]. O principal ponto fraco das teorias mais populares e que permite tal hipótese é a incapacidade experimental de se obter um valor numérico para a expansão acelerada do Universo, de modo que só é possível dizer se o mesmo está ou não acelerado, não se podendo estimar quanto. Os pesquisadores acreditam que essa característica é em parte devido ao princípio da relatividade de Galilei, mas se considerarmos a aceleração como quantidade absoluta é possível estimar uma aceleração de $\mathrm{a}=6,9$ $\mathrm{Km} 2 /(\mathrm{s} 2 . \mathrm{pc})$, supondo que a lei de Hubble é válida[10].

Nesse artigo fizemos uma exposição do estado da arte de energia escura. Fundamentamos nossa análise na perspectiva histórica e procuramos apontar as principais abordagens presentes na literatura que explicariam a energia escura. Discutimos a idéia da constante cosmológica e do uso do campo escalar acoplado com a gravitação. Por outro lado mostramos uma abordagem alternativa que se baseia no conceito de que o que chamamos de energia escura seria apenas um efeito de referencial não-inercial.

eBFIS 2, 007-2 (2013)
[1] H. A. de Barros-Pereira, Revista Brasileira de Ensino de Física 33, 2602 (2011).

[2] M. Ramos, Boletim do IGeoE , 4 (1999).

[3] J. Norton, JSTOR/Historical Studies in the Physical Sciences 14, 253 (1984).

[4] R. d'Inverno, Introducing Einstein's Relativity, 4th ed. (Clarendon Press, Oxford, 1996).

[5] E. Hubble, The Observational Approach to Cosmology (Oxford University Press, 1937).
[6] A. G. Riess et al. (Supernova Search Team), Astron. J. 116, 1009 (1998), arXiv:astro-ph/9805201.

[7] P. J. Peebles and B. Ratra, Rev. Mod. Phys. 75, 559 (2003), arXiv:astro-ph/0207347.

[8] O. Sergijenko and B. Novosyadlyj, Kinematics and Physics of Celestial Bodies 24, 259 (2008).

[9] S. C. Ulhoa, Annalen der Physik 524, 273 (2012). 